\title{
Natural environmental water sources in endemic regions of northeastern Brazil are potential reservoirs of viable Mycobacterium leprae
}

\author{
Maria Luisa Bezerra de Macedo Arraes ${ }^{1}$, Maísa Viana de Holanda', \\ Luana Nepomuceno Gondim Costa Lima², José Antônio Beltrão Sabadia ${ }^{3}$, Cynthia Romariz Duarte ${ }^{3}$, \\ Rosa Livia Freitas Almeida ${ }^{4}$, Carl Kendall ${ }^{5}$, Ligia Regina Sansigolo Kerr ${ }^{6}$, Cristiane Cunha Frota ${ }^{1 /+}$ \\ ${ }^{1}$ Universidade Federal do Ceará, Faculdade de Medicina, Departamento de Patologia e Medicina Legal, Fortaleza, CE, Brasil \\ ${ }^{2}$ Instituto Evandro Chagas, Seção de Bacteriologia e Micologia, Belém, PA, Brasil \\ ${ }^{3}$ Universidade Federal do Ceará, Departamento de Geologia, Fortaleza, CE, Brasil \\ ${ }^{4}$ Universidade de Fortaleza, Programa de Pós-Graduação em Saúde Coletiva, Fortaleza, CE, Brasil \\ ${ }^{5}$ Tulane University, School of Public Health and Tropical Medicine, Department of Global Community Health and Behavioral Sciences, \\ New Orleans, LA, USA \\ ${ }^{6}$ Universidade Federal do Ceará, Faculdade de Medicina, Departamento de Saúde Comunitária, Fortaleza, CE, Brasil
}

BACKGROUND The detection of live Mycobacterium leprae in soil and animals other than humans suggests that the environment plays a role in the transmission of leprosy.

OBJECTIVE The objective of this study was to investigate the presence of viable M. leprae in natural water sources used by the local population in five municipalities in the state of Ceará, northeastern Brazil.

METHODS Samples were collected from 30 different sources. Viable bacilli were identified by reverse transcriptase polymerase chain reaction (PCR) of the $M$. leprae gyrA gene and sequencing of the PCR products. Physicochemical properties of each water source were also assessed.

FINDINGS $M$. leprae gyrA mRNA was found in 23 (76.7\%) of the water sources. No association was found between depth of the water and sample positivity, nor was there any association between the type of water used by the population and sample positivity. An association between viable $M$. leprae and temperature and $\mathrm{pH}$ was found. Georeferencing showed a relation between the residences of leprosy cases and water source containing the bacterium.

MAIN CONCLUSIONS The finding of viable $M$. leprae in natural water sources associated with human contact suggests that the environment plays an important role in maintaining endemic leprosy in the study region.

Key words: Mycobacterium leprae - water - mRNA - leprosy - disease transmission

Leprosy is a public health problem, especially in developing countries. The main mode of transmission of Mycobacterium leprae, the leprosy-causing agent, is inhalation of infectious aerosols released by untreated cases with the multibacillary (MB) clinical form of the disease. However, the detection of live bacilli in the peridomiciliary soil of cases suggests that the environment may also play a role in the disease transmission (Turankar et al. 2016). Other studies have identified possible non-human sources of the bacillus (Truman \& Fine 2010), including water (Wahyuni et al. 2010), plants (Mostafa et al. 1995), armadillos (Frota et al. 2012, Kerr et al. 2015), primates (Gormus et al. 1998), and insects (Neumann et al. 2016).

The role of the environment as a route of disease transmission is supported by reports of leprosy cases with no history of previous contact with another case (Marcos et al. 2015), the detection of new cases close to sources of water (Kerr-Pontes et al. 2006), and high

doi: 10.1590/0074-02760170117

Financial support: CNPq (CT-HIDRO/CT-SAÚDE/CNPq 45/2008 - Water and Public Health, 577028/2008-1).

+ Corresponding author: cristianefrota71@gmail.com

Received 23 March 2017

Accepted 30 June 2017 seropositivity to anti-phenolic glycolipid-l (PGL 1) in communities with no leprosy cases (Frota et al. 2010).

Brazil, India, and Indonesia account for $81 \%$ of all new cases identified globally each year (WHO 2015). In Ceará state, northeastern Brazil, leprosy remains endemic, with the rate of detection of new cases in children under 15 years of age increasing slightly, from 5.4/100,000 inhabitants in 2010 to $6.1 / 100,000$ inhabitants in 2014. In Ceará, in 2015, $80.5 \%$ of the municipalities registered new cases of the disease (SESA 2016).

The use of molecular techniques to detect nucleic acids and methodologies that inactivate amplification inhibitors has permitted the detection of mRNA in environmental samples. Because M. leprae does not grow in axenic media, detection of mRNA from specimens has been employed to determine the presence of viable $M$. leprae (Davis et al. 2013). In mycobacteria, ribosome degradation is one of the first ultrastructural signs of loss of viability; it precedes bacteriolysis (Silva et al. 1987). However, the half-life of mRNA varies for each transcript, and it is also related to RNase E activity and bacterial adaptation to changes in growth conditions (Esquerre et al. 2015). Therefore, the survival time of $M$. leprae mRNA remains unknown.

In the present study, we investigated the presence of viable $M$. leprae in environmental water samples from 
five municipalities in the state of Ceará: Boa Viagem, Crato, Juazeiro do Norte, Mulungu, and Sobral. We extracted mRNA from the environmental samples and then perform reverse transcriptase-polymerase chain reaction (RT-PCR) amplification and sequencing of gyrA.

\section{MATERIALS AND METHODS}

Description of the study areas - In this study, water samples from the municipalities of Boa Viagem, Crato, Juazeiro do Norte, Mulungu, and Sobral, located in the state of Ceará in the northeastern region of Brazil, were assessed. All water samples were collected from November 2011 to December 2014. The municipalities were selected based on leprosy epidemiology, as well as geological and climatic conditions. The municipalities had the following rates (new cases/10,000 inhabitants) of leprosy detected in 2012: 7.6 in Boa Viagem, 32.1 in Crato, 38 in Juazeiro do Norte, 0 in Mulungu, and 45.2 in Sobral (SESA 2016). The climate in each municipality is semi-arid and hot, except in Mulungu, which is slightly more humid.

The water samples were obtained from natural sources such as reservoirs, rivers, streams, springs, and wells. The collection points were selected by local health agents because they are used by the population for leisure and/ or domestic purposes (drinking, bathing, washing dishes, washing clothes, and tending animals). Samples were collected from five sites in Juazeiro do Norte, from eight sites in Sobral, and from four sites in Crato. In the municipalities of Boa Viagem and Mulungu, samples were collected from seven and six sites, respectively (Fig. 1).

Water sample collection - At each collection site, five samples were obtained from different depths identified by the letters "a" through "e" (surface, $25 \mathrm{~cm}, 50 \mathrm{~cm}, 75 \mathrm{~cm}$, and $100 \mathrm{~cm}$ ). In addition, the samples from each site were identified by the initial of the municipality [Boa Viagem
(B); Crato (C); Juazeiro do Norte (J); Mulungu (M); and Sobral (S)], followed by the numerical order (B1 to B7; $\mathrm{C} 1$ to $\mathrm{C} 4$; J1 to J5; M1 to M6 and S1 to S8) and the replicates in alphabetical order (B1a, B1b, B1c, B1d, B1e, B2a ... B7e). The waters were collected in a Van Dorn bottle, which allows the collection of water from the sub-surface to the bottom of a water source, trapping water at the selected depth. Immediately after water collection, physicochemical parameters (electrical conductivity, $\mathrm{pH}$, and temperature) were measured. Water samples were then packed in sterile amber $1000-\mathrm{mL}$ bottles and transported in styrofoam containers with ice within $24 \mathrm{~h}$ to the laboratory located in the capital of Ceará. During transport from the municipality to the capital city, one sample from the municipality of Boa Viagem (replica B7d) was damaged; the remaining 149 environmental samples from 30 sites were successfully delivered.

Nucleic acid extraction - The entire 1000-mL volume of each water sample was initially vacuum-filtered through a Mo Bio ${ }^{\circledR}$ filter with a sterile $0.22-\mu \mathrm{m}$ membrane. Using two sets of sterile forceps, the filter membrane containing the sediment was rolled with the top side facing inward and placed into a tube containing glass beads from a Power Water RNA Isolation Kit (Mo Bio $\left.{ }^{\circledR}\right)$. The total RNA was then extracted according to the manufacturer's instructions. Prior to recovering RNA, samples were incubated with DNase I stock enzyme (Mo Bio $($ ) for $15 \mathrm{~min}$ at $25^{\circ} \mathrm{C}$. Total RNA was stored at $-80^{\circ} \mathrm{C}$. A negative control for the RNA extraction was included with each set of water samples processed, using sterile distilled water in place of the environmental samples.

Standard care was taken to prevent degradation and contamination during all of the extraction and purification steps, which included the use of sterile disposables previously treated with diethyl pyrocarbonate (DEPC)

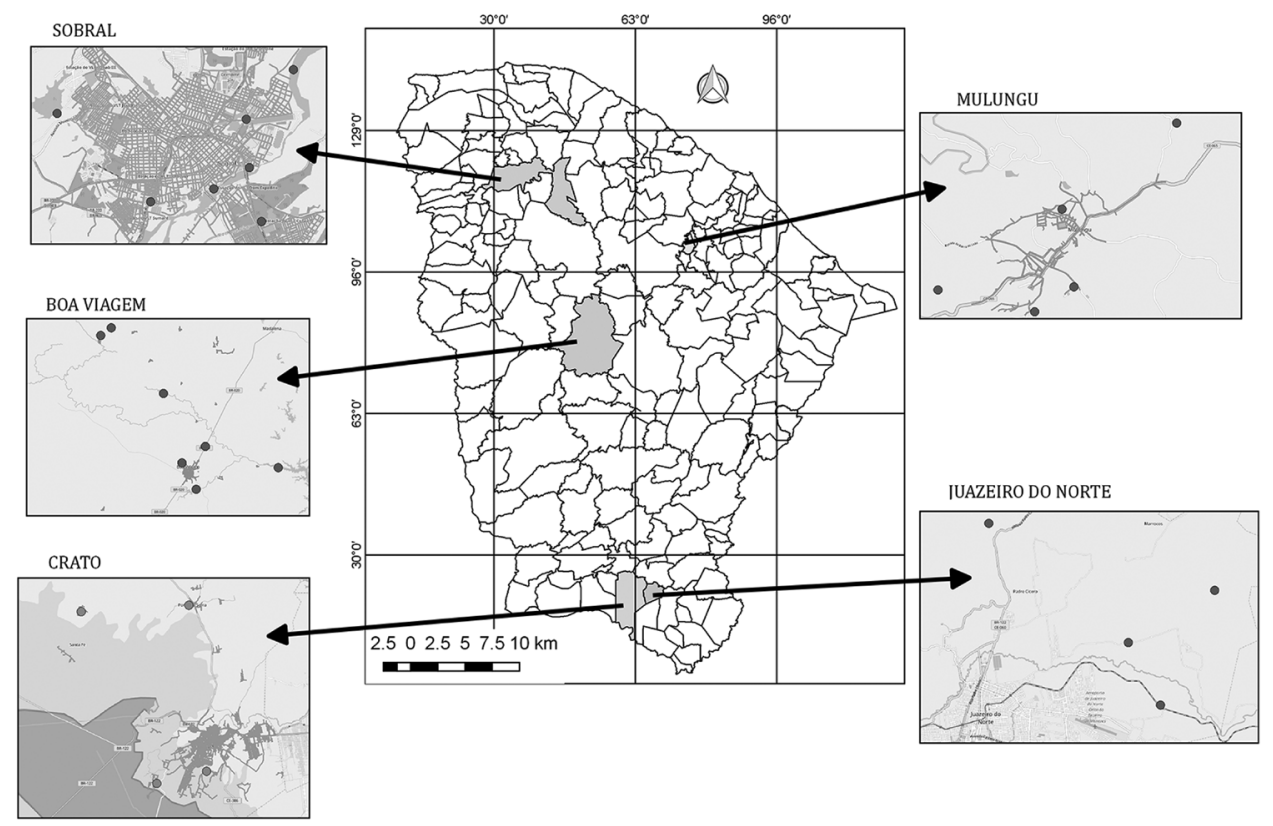

Fig. 1: locations of water sources in the municipalities of Boa Viagem, Crato, Juazeiro do Norte, Mulungu, and Sobral, in the state of Ceará, Brazil. Grey dots $(\bullet)$ indicate the sites of water collection in each municipality. 
and sterile buffers prepared with DEPC-treated water. We also used sterile filter tips in all procedures.

RT-PCR of the M. leprae gyrA gene - The PCR primers used to detect viable $M$. leprae were designed using the Primer3Plus program and targeted a 3750-bp ML0006 genomic region ( gyrA) of M. leprae, GenBank accession No. Q57532. The 187-bp product, located between bases 7515 and 7702 of gyrA, was amplified with the primers gyrA-forward 5'-CCC GGA CCG TAG CCA CGC TAA GTC-3' and gyrA-reverse 5'-ATC GCT GCC GGT GGG TCA TTA-3'. The gyrA transcripts were selected because of their role as an essential bacterial enzyme. In addition, $M$. leprae codes for a homologue endoribonuclease (RNAseE) that plays a central role in mRNA degradation (Cole et al. 2001) and in the gyrA message (Unniraman et al. 2002).

Reverse transcriptase, followed by amplification, was performed using a OneStep RT-PCR Kit (Qiagen), with a $50 \mu \mathrm{L}$ reaction consisting of $10 \mu \mathrm{L}$ of $5 \times$ RT-PCR Buffer, $2.5 \mu \mathrm{L}$ of total extracted RNA, $0.5 \mu \mathrm{L}$ of each primer, $2 \mu \mathrm{L}$ of RT-PCR Enzyme Mix, $2 \mu \mathrm{L}$ of dNTP mix $(10 \mathrm{mM})$, and a sufficient volume of RNase-free water. In each run, $20 \mathrm{pg}$ of $M$. leprae DNA (extracted from a leprosy case by biopsy) was included as a positive control, and, as a negative control, we used $2.5 \mu \mathrm{L}$ of RNase-free $\mathrm{H}_{2} \mathrm{O}$ in place of a nucleic acid template.

The reverse transcription reaction occurred at $50^{\circ} \mathrm{C}$ for $5 \mathrm{~min}$, followed by denaturation at $95^{\circ} \mathrm{C}$ for $15 \mathrm{~min}$. Amplification occurred with initial heating at $94^{\circ} \mathrm{C}$ for 5 min, followed by six cycles of denaturation at $94^{\circ} \mathrm{C}$ for 45 sec, annealing at $65^{\circ} \mathrm{C}$ for $30 \mathrm{sec}$, extension at $72^{\circ} \mathrm{C}$ for 90 sec, and then 35 denaturation cycles at $94^{\circ} \mathrm{C}$ for $45 \mathrm{~min}$, annealing at $62^{\circ} \mathrm{C}$ for $45 \mathrm{sec}$, extension at $72^{\circ} \mathrm{C}$ for $45 \mathrm{sec}$, and a final extension at $72^{\circ} \mathrm{C}$ for $10 \mathrm{~min}$. After amplification, the products were visualised by separation on a $1 \%$ (w/v) agarose gel stained with ethidium bromide solution. The fragments were visualised under ultraviolet light.

Sequencing and alignment of M. leprae gyrA amplification products - The PCR products were purified using a QIAquick PCR Purification Kit and then sequenced on an ABI 3130 Genetic Analyzer (Perkin-Elmer Applied Biosystems) using BigDye Terminator v3.1 Cycle Sequencing (Applied Biosystems) and BigDye XTerminator Purification (Applied Biosystems) kits. The sequences were converted to FASTA format using BioEdit Sequence Alignment v. 7.2.5, and then the basic local alignment search tool (BLAST) at NCBI (http://www.ncbi.nlm.nih.gov/) was applied. The taxonomic identities of the products were determined by comparison with the search results. The search result aligned our amplification products with the sequences of M. leprae BR4923 (GenBank accession No. FM211192), M. leprae TN chromosome (GenBank accession No. AL583917), M. leprae cosmid B1770 (GenBank accession No. Z70772), and M. leprae DNA gyrase subunit A gene (GenBank accession No. Z68206).

Statistical analysis - The data were entered into Microsoft $\AA$ Excel 2013 and transferred to SPSS 16.0 statistical software (SPSS Inc., USA) to conduct descriptive and bivariate analyses. Fisher and Chi-square tests were used, with $p$ values $<0.05$ considered significant.
Spatial analysis - The home addresses of all new leprosy cases detected in Sobral in 2011 and the site of each of the water sources were georeferenced using Google Earth (https://www.google.com/earth/) to define latitude and longitude. After the exclusion of possible inconsistencies, such as sites located outside municipal boundaries and coordinates not determined because of incomplete addresses, the spatial database was visualised using QuantumGis Geographic Information System 18.1.0â, licensed by General Public License) (http:// www.qgisbrasil.org). We used the georeferenced shapefile of municipalities in the state of Ceará (shapefile Arquive), available at the Brazilian Institute of Geography and Statistics [Instituto Brasileiro de Geografia e Estatística (IBGE 2016)], to prepare the maps. Based on the points formed by the geographic coordinates of the addresses of water source collection points in Sobral, Voronoi diagrams were created, with the polygons showing the proximity between cases and water sources. Geolocated residential addresses of leprosy cases in the other four municipalities were not available.

\section{RESULTS}

Of the 30 water sources analysed, viable $M$. leprae was found in $23(76.7 \%)$. Of the 30 , there were two sources with five $(6.7 \%)$ positive water samples, one source with four samples, eight $(26.7 \%)$ sources with three and two positive samples, and four sources with only one (13.3\%) positive sample. Regarding the municipalities, M. leprae was found in all sources in Juazeiro do Norte and Crato. In Sobral, six of the eight sources (75.0\%) were positive. In Mulungu and Boa Viagem, M. leprae bacilli were found in four of six (66.7\%) and four of seven (57.1\%) sources, respectively (Table). No differences were found in positivity in relation to the type of source (reservoir, pond, spring, river, stream, or well). Similarly, no differences in positivity were found in relation to the type of water use (human, human/animal, irrigation, irrigation/ animal). Most of the water sources $(27 ; 90 \%)$ were used for domestic purposes (drinking, bathing, cooking, washing clothes/dishes, recreational), with three sources used indirectly for humans, i.e., for irrigation and animal use.

M. leprae bacilli were detected in nine (30.0\%) water samples collected at the surface, 11 (36.7\%) samples each were found at $25-\mathrm{cm}$ and $50-\mathrm{cm}$ depth, $14(46.7 \%)$ water samples were found at $75-\mathrm{cm}$ depth and at $100-\mathrm{cm}$ depth, and $15(50.0 \%)$ samples at $100-\mathrm{cm}$ depth were found.

The BLAST search results confirmed that the product sequences were those of $M$. leprae gyrA. The cDNA sequences from the water samples were aligned with the $M$. leprae cosmid Br4923 (FM211192), M. leprae Tamil Nadu strain (AL583917), M. leprae cosmid B1770 (Z70722), and M. leprae DNA gyrase subunit A gene (Z68206) sequences, with $99 \%$ and $100 \%$ similarities observed for all sequences.

Physicochemical parameters indicating quality were measured at the time of water sample collection (Supplementary data, Table). The mean electrical conductivity for all sources was $529.6 \pm 344.5 \mu \mathrm{S} / \mathrm{cm}$, with a mean of $574.2 \pm 350.3$ for water that was negative for the $M$. leprae, and $462.7 \pm 314.6$ for water that was positive. This difference was statistically significant $(\mathrm{p}=$ 0.044). Minerals were present, but no differences were 
TABLE

Distribution of Mycobacterium leprae mRNA positivity in the five municipalities of Ceará, Brazil, by type of source and purpose use of the water

\begin{tabular}{|c|c|c|c|c|}
\hline Municipality & Place & Type of source & positive RNAm N (\%) ${ }^{a}$ & Purpose of use \\
\hline \multirow[t]{6}{*}{ Juazeiro do Norte $(\mathrm{N}=25)$} & $\mathrm{J} 1$ & dam & $2(40.0)$ & human \\
\hline & $\mathrm{J} 2$ & dam & $2(40.0)$ & human/animal \\
\hline & $\mathrm{J} 3$ & stream & $2(40.0)$ & human \\
\hline & $\mathrm{J} 4$ & dam & $5(100.0)$ & human \\
\hline & $\mathrm{J} 5$ & stream & $4(80.0)$ & human \\
\hline & & total & $15(60.0)$ & \\
\hline \multirow[t]{5}{*}{ Crato $(\mathrm{N}=20)$} & $\mathrm{C} 1$ & resort & $2(40.0)$ & human \\
\hline & $\mathrm{C} 2$ & dam & $3(60.0)$ & human \\
\hline & $\mathrm{C} 3$ & dam & $3(60.0)$ & human \\
\hline & $\mathrm{C} 4$ & dam & $1(20.0)$ & human/animal \\
\hline & & total & $9(45.0)$ & \\
\hline \multirow[t]{9}{*}{ Sobral $(\mathrm{N}=40)$} & $\mathrm{S} 1$ & dam & $1(20.0)$ & human \\
\hline & $\mathrm{S} 2$ & dam & 0 & human \\
\hline & $\mathrm{S} 3$ & lake & $2(40.0)$ & irrigation \\
\hline & $\mathrm{S} 4$ & river & $3(60.0)$ & human \\
\hline & S5 & river & $3(60.0)$ & human \\
\hline & S6 & stream & $3(60.0)$ & human \\
\hline & S7 & shallow river & 0 & human/animal \\
\hline & S8 & shallow river & $2(40.0)$ & human/animal \\
\hline & & total & $14(35.0)$ & \\
\hline \multirow[t]{8}{*}{ Boa Viagem $(\mathrm{N}=34)$} & B1 & dam & $5(100.0)$ & human \\
\hline & B2 & dam & 0 & human \\
\hline & B3 & dam & 0 & human \\
\hline & B4 & dam & $3(60.0)$ & human \\
\hline & B5 & dam & $2(40.0)$ & human/animal \\
\hline & B6 & dam & $3(60.0)$ & human \\
\hline & B7 & dam & 0 & human \\
\hline & & total & $13(38.2)$ & \\
\hline \multirow[t]{7}{*}{ Mulungu $(\mathrm{N}=30)$} & M1 & lake & 0 & animal/irrigation \\
\hline & M2 & well & $1(20.0)$ & human \\
\hline & M3 & well & $1(20.0)$ & human \\
\hline & M4 & well & $2(40.0)$ & human \\
\hline & M5 & stream & 0 & animal/irrigation \\
\hline & M6 & well & $3(60.0)$ & human \\
\hline & & total & $7(23.3)$ & \\
\hline
\end{tabular}

$\mathrm{a}: \mathrm{p}=0.0807$, Chi-square test comparison of the mRNA positivity of the five municipalities.

found in electrical conductivity between the positive and negative samples from the five municipalities. No differences in electrical conductivity were found among water samples collected at different depths (surface to 1 $\mathrm{m})$ from the same source. The mean temperature of all sources was $28.6 \pm 2.5^{\circ} \mathrm{C}$, with no difference between the positive $\left(28.1 \pm 2.2^{\circ} \mathrm{C}\right)$ and negative $\left(28.8 \pm 2.7^{\circ} \mathrm{C}, \mathrm{p}\right.$ $=0.156$ ) samples. However, significant differences were observed between the temperatures of the positive $(27.2$ $\left.\pm 0.5^{\circ} \mathrm{C}\right)$ and negative $\left(28.3 \pm 2.0^{\circ} \mathrm{C} ; \mathrm{p}<0.025\right)$ samples from the municipality of Boa Viagem. According to the World Health Organization (WHO 2011), pH has no health impact on consumers, but it is considered as an important parameter indicating water quality. The $\mathrm{pH}$ of an ideal water source has been proposed to vary between 6.5 and 8.0. The studied water sources were alkaline, with a mean $\mathrm{pH} 7.8 \pm 1.0$. Only Sobral showed significant differences in $\mathrm{pH}$ in relation to $M$. leprae positivity, with a mean $\mathrm{pH}$ of $7.3 \pm 0.4$ in the positive samples and $8.3 \pm 1.1$ in the negative ones $(\mathrm{p}=0.001)$. 
M. leprae mRNA was found in water sources $\mathrm{J} 4$ and $\mathrm{B} 1$, in replicates collected at all depths, whereas samples S2, S7, B2, B3, B7, M1, and M5 all were negative. When comparing the mean values of the physicochemical parameters of sources $\mathrm{J} 4$ and $\mathrm{B} 1$ in and those of $\mathrm{S} 2, \mathrm{~S} 7$, $\mathrm{B} 2, \mathrm{~B} 3, \mathrm{~B} 7, \mathrm{M} 1$, and $\mathrm{M} 5$, positive samples were observed to have a mean temperature of $28.3 \pm 0.68^{\circ} \mathrm{C}$, whereas the negative sources had a mean temperature of $29.4 \pm$ $3.24^{\circ} \mathrm{C}(\mathrm{p}=0.015, t$-test for independent samples). The same comparisons for electrical conductivity and $\mathrm{pH}$ between these positive and negative sources were conducted, but no significant differences were found (electrical conductivity, $\mathrm{p}=0.055 ; \mathrm{pH}, \mathrm{p}=0.120$ ).

Fig. 2 shows the map of the municipality of Sobral, with the location of the water sources analysed in this study and the residences of new MB and paucibacillary (PB) leprosy cases detected in year 2011. No viable $M$. leprae bacilli were found in samples S2 (reservoir) and S7 (river). These two sources were located far from the main river, and only one new case of leprosy was detected in their respective Voronoi polygons. In contrast, several new cases of MB and PB leprosy were detected close to sources S1, S3, S4, S5, S6, and S8. Points S1, S3, S4, S5, and $\mathrm{S} 6$ are located within the urban area of the municipality of Sobral. The main river runs towards the Atlantic Ocean, and therefore the bacilli present at point S6 could flow towards S5, then S4, and finally S8. At point S8 (positive for M. leprae mRNA), which is outside the city limits, only one new case of leprosy was detected in 2011.

\section{DISCUSSION}

Leprosy is considered endemic in the northern and northeastern regions of Brazil. In 2015, in the state of Ceará, approximately $18.4 \%$ of municipalities were classified as hyperendemic, with more than 40 new cases per 100,000 inhabitants (SESA 2016). In many places, especially in remote areas of the northern and northeastern regions, access to health services is deficient, delaying the diagnosis of new cases and contributing to disease dissemination.

Several studies have suggested the role of the environment in disease transmission (Truman \& Fine 2010, Mohanty et al. 2016). Our study is the first to report the presence of viable M. leprae in water sources in the American continent. The bacterium was identified in several natural water sources in five municipalities of the state of Ceará, Brazil. Viable bacilli were found in all five studied municipalities. Moreover, viable M. leprae was more frequently detected in municipalities with higher disease endemicity (Juazeiro do Norte, Crato, and Sobral) as compared to municipalities with lower endemicity (Boa Viagem and Mulungu). Other studies conducted in Asia have shown the presence of M. leprae DNA in rivers, wells, and lakes in a hyperendemic region in North Maluku, Indonesia (Matsuoka et al. 1999), and via-

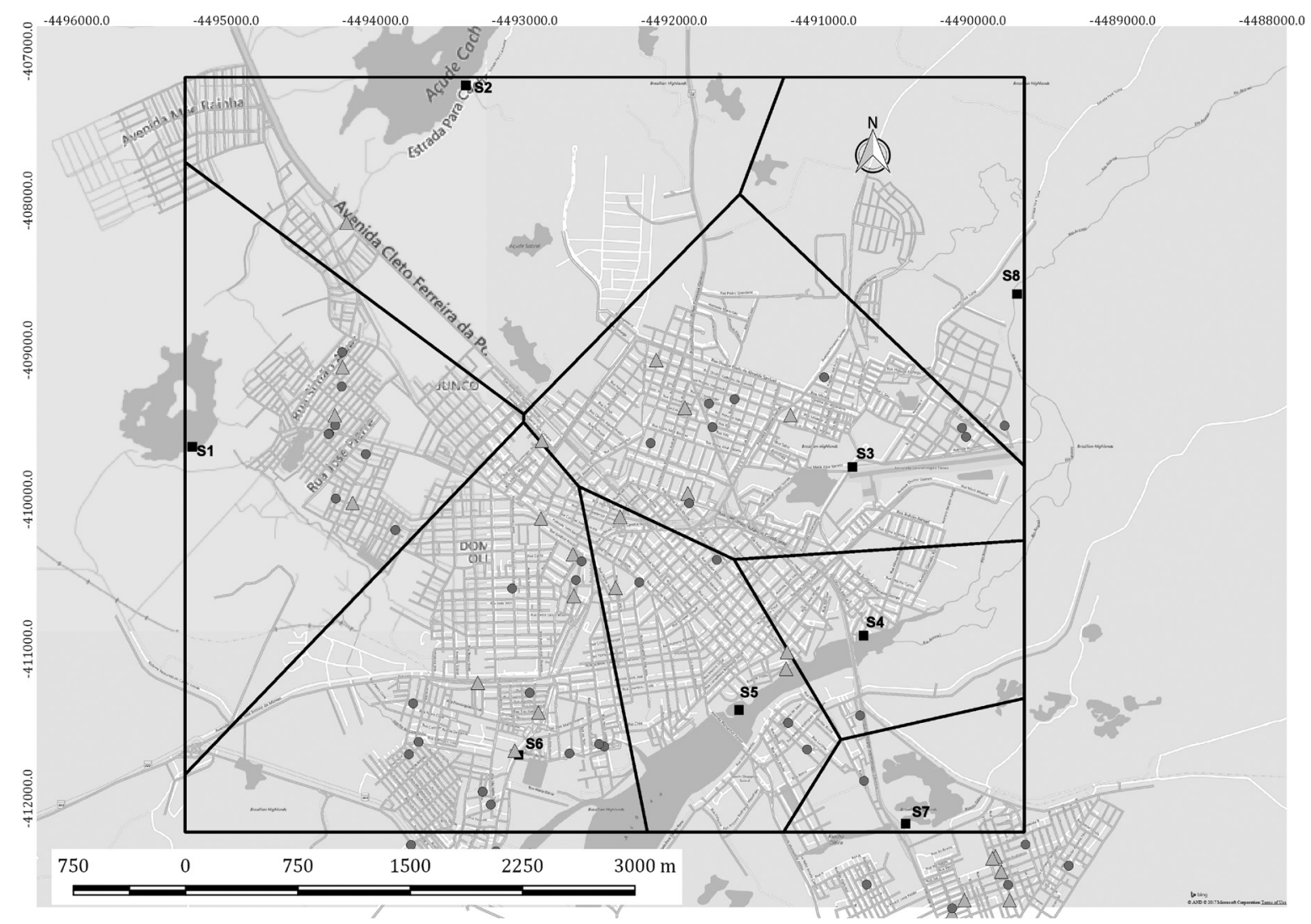

Fig. 2: map of the city of Sobral, state of Ceará, Brazil, showing new leprosy cases detected in 2011 and sites where water was collected (S1 to S8). The grey squares ( $\bullet$ indicate the water collection sites, black dots $(\bullet)$ show the residences of multibacillary cases, and the grey triangles $(\boldsymbol{\Lambda})$ indicate the residences of paucibacillary leprosy cases. Lines represent the Voronoi diagram. 
ble bacilli in sewers and wells of endemic regions in India (Mohanty et al. 2016). A recent study also conducted in the state of Ceará, Brazil, demonstrated the presence of genotype $4 \mathrm{M}$. leprae in environmental waters (Holanda et al. 2017). Other studies have shown the presence of viable bacilli in the peridomestic soil of leprosy cases in the Ghatampur and Purulia districts in India (Mohanty et al. 2016, Turankar et al. 2016). Future studies using genotyping techniques, including whole genome sequencing, are necessary to evaluate the similarity between the bacilli found in the environment and that found in patients.

Armadillos are known to be natural reservoirs of $M$. leprae, and contact with these animals is considered a risk factor for leprosy (Balamayooran et al. 2015, Kerr et al. 2015). In studies carried out in the southeastern United States, the same genotype of M. leprae was found in armadillos and human leprosy cases (Sharma et al. 2015). The study patients reported no direct contact with the animals, but they had direct contact with wild areas. In the state of Ceará, armadillos are commonly found in nature; hunting these animals is a leisure activity, and their meat is widely consumed in the countryside.

Studies carried out in Ceará, with animals captured at different sites, indicated that $21 \%$ of the animals carried M. leprae DNA (Frota et al. 2012), and another study in the state suggested that interaction with armadillos were a risk factor for transmission (Kerr et al. 2015). However, the role of the armadillo in this chain of disease transmission involving soil, water, humans, and other living beings is yet to be elucidated.

Northeastern Brazil has two climatic seasons, a dry season and a rainy season. The rains are concentrated in four months of the year, from February to May, and are influenced by the Intertropical Convergence Zone. However, the short rainy season has a highly variable intensity, influenced by the temperatures in the Atlantic Ocean. The countryside of Ceará is a semi-arid region, with rainfall intensity decreasing each year and temperatures reaching $40^{\circ} \mathrm{C}$ (Barroso et al. 2016). Therefore, the building of dams for water storage is common. In our study, $50 \%$ of the water sources analysed were reservoirs associated with dams. The few rivers found in the state of Ceará have shown reductions in volume annually or have become completely dry. Therefore, water sources are important and serve multiple purposes such as providing leisure activities, domestic use, and animal and agricultural use. Even in the wells in Mulungu, a mountainous region, people bathe and wash objects near the well. In our study, $90 \%$ of the water sources were heavily used by the local population for a variety of purposes. Patients with the MB form of the disease release bacilli into the environment through body secretions, and the bacillus can survive in the environment for a variable amount of time. Bacillus have been shown to remain viable up to 45 days and up to eight months within amoebas (Wheat et al. 2014). As demonstrated in Sobral, viable bacilli were found in water sources (S1 and S3 to S6) close to the domiciles of leprosy cases. Interestingly, sample S8, with only one case of the disease reported nearby, was also positive for M. leprae. This finding can be explained by the direction of the river flow in the municipality of Sobral. The river flows from west to east, going towards the Atlantic Ocean. The main river receives water from stream S6 and continues towards the Atlantic Ocean, with water sources found the following order downstream: S6, S5, S4, and S8. In the regions near sources S2 and S7 (negative for M. leprae mRNA), which are distant from the main river, only one case of leprosy was detected in each.

The finding of $M$. leprae in six water sources out of a total of eight in the municipality of Mulungu confirms what we suggested in the report of a study carried out with anti-PGL-1 in that population (Frota et al. 2010). Mulungu is a small isolated mountain town with a mild climate compared to that of other cities in the state of Ceará and with a leprosy prevalence of less than 1 case per 100,000 inhabitants. In our study conducted in 2010, seropositivity to anti-PGL-1 in Mulungu was $14 \%$, similar to that found in the municipality of Sobral (endemic for leprosy), which was $15 \%$. Mulungu is surrounded by five municipalities, which, in 2011, had case detection rates varying from zero to $53.4 / 100,000$ inhabitants (DATASUS 2017). We suggest that leprosy detection is underestimated by the local government health agency and that this could have implications for the maintenance of disease in the region. In addition, we suggest that transmission of leprosy does not occur only through human contact, but that the environment also plays an important role in transmission of the disease. As suggested by another epidemiological study carried out in Ceará (Kerr-Pontes et al. 2006), bathing in natural water sources is a risk factor for leprosy.

M. leprae has been shown to survive in free-living pathogenic amoeba in vitro (Wheat et al. 2014). Furthermore, one study suggested that the ancestor of mycobacteria was an environmental organism living in an aquatic habitat (Ahmed et al. 2007). The association between viable $M$. leprae in water sources, particularly those used by the community, highlights the possible role of a protozoan or other organism in prolonging survival of the bacteria in the environment, including in soil and water.

We investigated the physicochemical properties of the collected water samples, and found that temperature and $\mathrm{pH}$ were only associated with the presence of live M. leprae only in Boa Viagem and Sobral. Positive water samples were also associated with significantly lower temperatures than those found in negative sources. However, it is difficult to infer the relevance of water temperature and the maintenance of the bacillus in these water sources.

Our results are consistent with the literature in associating water with leprosy cases. We emphasise the importance of demonstrating the presence of viable $M$. leprae. Future studies are necessary to demonstrate the linkage between $M$. leprae found in water and human infections through genotyping. We also suggest that early diagnosis of cases, along with the geolocation of residence, schools, and worksites, is important to monitor the emergence of new secondary cases.

\section{ACKNOWLEDGEMENTS}

To the support and participation of the local health authorities and the health agents of Boa Viagem, Crato, Juazeiro do Norte, Mulungu, and Sobral, Brazil. 


\section{AUTHORS' CONTRIBUTION}

MLBMA - Laboratory assays, data analysis, writing, editing; MVH and LNGCL - laboratory assays, data analysis, editing; JABS and CRD - water samples collections, on-location research coordination, data gathering, data analysis; RLFA - data analysis, database support, writing; CK and LRSK project design, data analysis, writing, editing; CCF - research project design, data analysis, writing, editing, corresponding author. All authors read and approved the final manuscript.

\section{REFERENCES}

Ahmed N, Saini V, Raghuvanshi S, Khurana JP, Tyagi AK, Tyagi AK, et al. Molecular analysis of a leprosy immunotherapeutic bacillus provides insights into Mycobacterium evolution. PLoS ONE. 2007; 2(10): e968.

Balamayooran G, Pena M, Sharma R, Truman RW. The armadillo as an animal model and reservoir host for Mycobacterium leprae. Clin Dermatol. 2015; 33(1): 108-15.

Barroso HSB, Becker H, Melo VMM. Influence of river discharge on phytoplankton structure and nutrient concentrations in four tropical semiarid estuaries. Braz J Oceanogr. 2016; 64(1): 37-48.

Cole ST, Eiglmeier K, Parkhill J, James KD, Thomson NR, Wheeler PR, et al. Massive gene decay in the leprosy bacillus. Nature. 2001; 409(6823): 1007-11

DATASUS. Casos de Hanseníase - Desde 2001 (SINAN) [database on the Internet]. Ministério da Saúde do Brasil. 2017 [updated 20th May 2017]. Available from: http://www2.datasus.gov.br/DATASUS/index.php?area $=0203 \& \mathrm{id}=31032752 \& \mathrm{VObj}=\mathrm{http}: / /$ tabnet . datasus.gov.br/cgi/tabcgi.exe?sinannet/hanseniase/cnv/hansw.

Davis GL, Ray NA, Lahiri R, Gillis TP, Krahenbuhl JL, Williams DL, et al. Molecular assays for determining Mycobacterium leprae viability in tissues of experimentally infected mice. PLoS Negl Trop Dis. 2013; 7(8): e2404.

Esquerre T, Moisan A, Chiapello H, Arike L, Vilu R, Gaspin C, et al. Genome-wide investigation of mRNA lifetime determinants in Escherichia coli cells cultured at different growth rates. BMC genomics. 2015; 16(1): 275-87.

Frota CC, Freitas MV, Foss NT, Lima LN, Rodrigues LC, Barreto $\mathrm{ML}$, et al. Seropositivity to anti-phenolic glycolipid-I in leprosy cases, contacts and no known contacts of leprosy in an endemic and a non-endemic area in northeast Brazil. Trans R Soc Trop Med Hyg. 2010; 104(7): 490-5.

Frota CC, Lima LNC, Rocha AS, Suffys PN, Rolim BN, Rodrigues LC, et al. Mycobacterium leprae in six-banded (Euphractus sexcinctus) and nine-banded armadillos (Dasypus novemcinctus) in Northeast Brazil. Mem Inst Oswaldo Cruz. 2012; 107(Suppl. 1): 209-13.

Gormus BJ, Murphey-Corb M, Martin LN, Baskin GB, Mack PA, Xu $\mathrm{K}$, et al. Impaired responses to Mycobacterium leprae antigens in rhesus monkeys experimentally inoculated with simian immunodeficiency virus and M. leprae. Lepr Rev. 1998; 69(1): 24-39.

Holanda MV, Marques LEC, Macedo MLB, Pontes MAA, Sabadia JAB, Kerr L, et al. Presence of Mycobacterium leprae genotype 4 in environmental waters in Northeast Brazil. Rev Soc Bras Med Trop. 2017; 50(2): 216-22.

IBGE - Instituto Brasileiro de Geografia e Estatística. Cidades@ [database on the Internet]. Ministério do Planejamento, Desenvolvimento e Gestão - Brasil. 2016. Available from: http://cidades.ibge. gov.br/xtras/uf.php?lang $=\&$ coduf $=23 \&$ search $=$ ceara .
Kerr L, Kendall C, Sousa CA, Frota CC, Graham J, Rodrigues L, et al. Human-armadillo interaction in Ceara, Brazil: potential for transmission of Mycobacterium leprae. Acta Trop. 2015; 152(2): 74-9.

Kerr-Pontes LR, Barreto ML, Evangelista CM, Rodrigues LC, Heukelbach J, Feldmeier H. Socioeconomic, environmental, and behavioural risk factors for leprosy in North-east Brazil: results of a case-control study. Int J Epidemiol. 2006; 35(4): 994-1000.

Marcos LA, Dobbs T, Walker S, Waller W, Stryjewska BM. Indigenous cases of leprosy (Hansen's disease) in Southern Mississippi. J Miss State Med Assoc. 2015; 56(7): 188-91.

Matsuoka M, Izumi S, Budiawan T, Nakata N, Saeki K. Mycobacterium leprae DNA in daily using water as a possible source of leprosy infection. Indian J Lepr. 1999; 71(1): 61-7.

Mohanty PS, Naaz F, Katara D, Misba L, Kumar D, Dwivedi DK, et al. Viability of Mycobacterium leprae in the environment and its role in leprosy dissemination. Indian J Dermatol Venereol Leprol. 2016; 82(1): 23-7.

Mostafa HM, Kazda J, Irgens LM, Luesse HG. Acid-fast bacilli from former leprosy regions in coastal Norway showing PCR positivity for Mycobacterium leprae. Int J Lepr Other Mycobact Dis. 1995; 63(1): 97-9.

Neumann AS, Dias FA, Ferreira JS, Fontes AN, Rosa PS, Macedo RE, et al. Experimental infection of Rhodnius prolixus (Hemiptera, Triatominae) with Mycobacterium leprae indicates potential for leprosy transmission. PLoS ONE. 2016; 11(5): e0156037.

SESA - Secretaria de Estado da Saúde. Boletim epidemiológico hanseníase. Coordenadoria de Promoção e Proteção à Saúde [serial on the Internet]. 2016. Available from: http://www.saude.ce.gov.br/index.php/boletins?download=813\%3Ahanseniase-janeiro-de-2012.

Sharma R, Singh P, Loughry WJ, Lockhart JM, Inman WB, Duthie MS, et al. Zoonotic leprosy in the southeastern United States. Emerg Infect Dis. 2015; 21(12): 2127-34.

Silva MT, Appelberg R, Silva MN, Macedo PM. In vivo killing and degradation of Mycobacterium aurum within mouse peritoneal macrophages. Infect Immun. 1987; 55(9): 2006-16.

Truman R, Fine PE. 'Environmental' sources of Mycobacterium leprae: issues and evidence. Lepr Rev. 2010; 81(2): 89-95.

Turankar RP, Lavania M, Singh M, Sengupta U, Siva Sai K, Jadhav RS. Presence of viable Mycobacterium leprae in environmental specimens around houses of leprosy patients. Indian J Med Microbiol. 2016; 34(3): 315-21.

Unniraman S, Chatterji M, Nagaraja V. A hairpin near the 5' end stabilises the DNA gyrase mRNA in Mycobacterium smegmatis. Nucleic Acids Res. 2002; 30(24): 5376-81.

Wahyuni R, Adriaty D, Iswahyudi I, Prakoeswa CRS. Mycobacterium leprae in Daily water resources of inhabitants who live in leprosy endemic area of east Java. Ind J Trop Infect Dis. 2010; 1(2): 65-8.

Wheat WH, Casali AL, Thomas V, Spencer JS, Lahiri R, Williams $\mathrm{DL}$, et al. Long-term survival and virulence of Mycobacterium leprae in amoebal cysts. PLoS Negl Trop Dis. 2014; 8(12): e3405.

WHO - World Health Organization. Acceptability aspects. In: Guidelines for drinking-water quality, 4th ed. Geneva: WHO Library Cataloguing-in-Publication Data; 2011. 409 pp.

WHO - World Health Organization. Global leprosy update, 2014: need for early case detection [database on the Internet]. 2015 [updated 4 September 2015; cited 12 May 2016]. Available from: http:// www.who.int/wer/2015/wer9036/en/. 